\title{
Produtividade da alface americana submetida a diferentes lâminas de irrigação
}

\section{Yield of crisphead lettuce under different amounts of irrigation}

\author{
Joaquim Alves de Lima Junior ${ }^{1 *}$; Geraldo Magela Pereira ${ }^{2}$; \\ Luciano Oliveira Geisenhoff ${ }^{3}$; Renato Carvalho Vilas Boas ${ }^{4}$; \\ Wellington Gomes da Silva ${ }^{4}$; Andre Luiz Pereira da Silva ${ }^{5}$
}

\begin{abstract}
Resumo
Visando reduzir as dificuldades do produtor no cultivo da alface (Lactuta sativa L) americana, especificamente quanto à falta de informações técnicas sobre a quantidade de água a ser aplicada, objetivou-se estudar o efeito de diferentes lâminas de água referentes às características produtivas dessa cultura. O experimento foi realizado na Universidade Federal de Lavras, no período de outubro a dezembro de 2008, em casa de vegetação. O delineamento experimental foi em blocos casualizados, com cinco tratamentos e quatro repetições. Os tratamentos foram cinco fatores de evaporação, correspondentes a 0,30 EVm; 0,60 EVm; 0,90 EVm; 1,20 EVm e 1,50 EVm (lâmina evaporada), baseado na lâmina evaporada de um minitanque. A máxima produtividade comercial, $36,5 \mathrm{t} \mathrm{ha}^{-1}$, foi estimada com a aplicação da lâmina de $164,8 \mathrm{~mm}$, correspondente ao fator de reposição de $98 \%$, sendo a maior eficiência no uso da água $\left(962,45 \mathrm{~kg} \mathrm{ha}^{-1} \mathrm{~mm}^{-1}\right)$ obtida com a aplicação da lâmina de irrigação de 50,10 mm, correspondente ao fator de reposição de água de 30\%.
\end{abstract}

Palavras-chave: Lactuta sativa L., minitanque, casa de vegetação

\begin{abstract}
With the aim of minimizing the difficulties faced by the producers on cultivating the crisphead lettuce (Lactuta sativa L), specifically those related to the lack of technical information about the quantity of water to be applied, a study was made in order to determine the effect of various water depths on crisphead lettuce yielding characteristics. The experiment was carried out at the Universidade Federal de Lavras, from October to December 2008 in greenhouse. A randomized block design with five treatments and four repetitions was applied. The treatments, consisting of the five respective evaporation factors; , 0.30 EVm; 0.60 EVm; 0.90 EVm; 1.20 EVm; $1.50 \mathrm{EVm}$ (evaporate depth), were done according to an evaporated depth of a reduced pan. The results showed that: The maximum commercial yield, 36.5 $\mathrm{t} \mathrm{ha}^{-1}$, was estimated by applying a $164.8 \mathrm{~mm}$ depth, which corresponded to a water reposition factor of $98 \%$; the highest water usage efficiency $\left(962.45 \mathrm{~kg} \mathrm{ha}^{-1} \mathrm{~mm}^{-1}\right)$ was attained when an irrigation depth of $50.10 \mathrm{~mm}(30 \%)$ was used.
\end{abstract}

Key words: Lactuta sativa L., irrigation depths, greenhouse

\footnotetext{
${ }^{1}$ Eng $^{\mathrm{o}} \mathrm{Agr}^{\mathrm{o}}$, Prof. Dr. Adjunto I do Dept ${ }^{\circ}$ de Ciências Exatas e Engenharia/DCEE, Universidade Federal Rural da Amazônia, UFRA, Paragominas, PA. E-mail: joaquim.junior@ufra.edu.br

${ }^{2}$ Eng $^{\mathrm{O}}$ Agrícola, Prof. Dr. Associado, Universidade Federal de Lavras, UFLA, Lavras, MG. E-mail: geraldop@deg.ufla.br

${ }^{3} \mathrm{Eng}^{\mathrm{o}} \mathrm{Agr}^{\mathrm{0}}$, Prof. Dr. Adjunto I, Universidade Federal da Grande Dourados, UFGD, Dourados, MS. E-mail: lucianogeisenhoff@, ig.com.br

${ }^{4}$ Engenheiros Agrônomos, Drs. em Engenharia de Água e Solo, UFLA, Lavras, MG. E-mail: renatovilasboas@yahoo.com.br; wellington1111@hotmail.com

${ }^{5} \mathrm{Eng}^{\mathrm{o}} \mathrm{Agr}^{\circ}$, Doutorando em Ciência do Solo, Universidade Estadual Paulista “Júlio de Mesquita Filho" UNESP, São Paulo, SP. E-mail: andreengagronomo@gmail.com

* Autor para correspondência
}

Recebido para publicação 23/04/1 1 Aprovado em 22/06/12 


\section{Introdução}

A alface (Lactuca sativa L.) é a principal hortaliça folhosa comercializada e consumida pela população brasileira pela facilidade de aquisição e por ser produzida durante o ano inteiro (OLIVEIRA et al., 2004). Ressalta-se que o volume de alface comercializado na CEAGESP-SP em 2007, foi de 28.389 toneladas, colocando-a, neste ano, na liderança nacional em comercialização e consumo (AGRIANUAL, 2008).

Dentre os tipos existentes de alface, merece destaque o plantio da alface tipo americana por atender a demanda principalmente as redes "fast foods" da região. Atualmente, no sul de Minas Gerais, um grupo de produtores dessa hortaliça tem produzido cerca de 1.000 t. brutas mês ${ }^{-1}$, apenas para abastecer uma grande rede de lojas (YURI et al., 2004). A alface americana se diferencia dos demais tipos por apresentar folhas externas de coloração verde-escura, folhas internas de coloração amarela ou branca, imbricadas semelhantes ao repolho e crocantes, além de maior vida pós-colheita, possibilitando o transporte a longas distâncias (YURI et al., 2002).

O cultivo em ambiente protegido é uma ferramenta muito útil para a aquisição de alta produção e de produtos de excelente qualidade, por manter um clima mais propício ao desenvolvimento da cultura ao longo do ano (SEGOVIA et al., 1997). Além disso, o cultivo protegido, dependendo menos das condições climáticas, pode amenizar possíveis infestações de pragas e doenças que ocorrem por conseqüência de precipitações inoportunas e oneram o custo de produção da cultura.

A alface é uma cultura exigente em água, sendo o manejo adequado da irrigação importante não apenas por suprir as necessidades hídricas das plantas, mas também por minimizar problemas com doenças e lixiviação de nutrientes, bem como gastos desnecessários com água e energia (KOETZ et al., 2006).

Segundo Volpe e Churata-Masca (1988), existem vários métodos para efetuar-se o manejo da água de irrigação e, dentre eles, destaca-se o do tanque Classe $\mathrm{A}$, devido à sua facilidade de operação, ao custo relativamente baixo e, principalmente, à possibilidade de instalação próxima à cultura a ser irrigada. No entanto, visando diminuir o custo do tanque Classe A e devido ao espaço reduzido no interior das casas de vegetação, tem-se adotado tanques de evaporação com dimensões reduzidas (minitanque), como alternativa para a estimativa da evapotranspiração.

Andrade Júnior e Klar (1997), estudando o efeito de quatro níveis de irrigação, baseado na evaporação do Tanque Classe A (ECA) $(0,25 ; 0,50$; 0,75 ; e 1,00), e utilizando irrigação por gotejamento na cultura da alface tipo americana, obtiveram valor máximo para produtividade total $90 \mathrm{t} \mathrm{ha}^{-1}$, com o nível de irrigação correspondente a $75 \%$ da ECA.

Silva et al. (2008) obteve efeito quadrático para circunferência da cabeça comercial da alface americana, cujo valor máximo de circunferência foi de $44,94 \mathrm{~cm}$, com uma lâmina total de água de $170,81 \mathrm{~mm}$, correspondente a $91,66 \%$ da lâmina de reposição.

Apesar da importância dos cultivos em ambientes protegidos para a olericultura brasileira, ainda são insuficientes os resultados de pesquisa que subsidiem o aproveitamento do potencial dessa tecnologia nas diferentes regiões climáticas do País, notadamente aqueles necessários ao adequado manejo da irrigação. Nesse aspecto, há necessidade de serem quantificados, dentre outros, os efeitos dos fatores climáticos sobre a evapotranspiração da cultura e os níveis de tensão de água do solo capazes de promover uma produtividade ótima, sendo essas informações imprescindíveis para o correto controle da irrigação pelos operadores e técnicos de projetos de irrigação (SANTOS; PEREIRA, 2004).

Nesse sentido, objetivo-se no trabalho em questão, avaliar o efeito de diferentes lâminas de irrigação sobre o comportamento produtivo da alface tipo americana, cv. Laureau, cultivada em ambiente 
protegido, na região de Lavras - $\mathrm{MG}$, visando a definir critérios para o manejo da irrigação.

\section{Material e Métodos}

O experimento foi desenvolvido em casa de vegetação situada na área experimental do Departamento de Engenharia da Universidade Federal de Lavras(UFLA), no período compreendido entre outubro a dezembro de 2008. A UFLA se situa em Lavras, sul de Minas Gerais, e está em uma altitude média de $910 \mathrm{~m}, 21^{\circ} 14^{\prime}$ latitude Sul e $45^{\circ}$ 00' longitude Oeste.

De acordo com a classificação de Köppen (DANTAS; CARVALHO; FERREIRA, 2007), a região apresenta clima Cwa, ou seja, clima temperado chuvoso (mesotérmico), com inverno seco e verão chuvoso, temperatura média do mês mais frio inferior a $18{ }^{\circ} \mathrm{C}$ e superior a $3{ }^{\circ} \mathrm{C}$; o verão apresenta temperatura média do mês mais quente superior a $22{ }^{\circ} \mathrm{C}$.

A casa de vegetação foi construída com estrutura metálica do tipo teto em arco, apresentando 2,5 $\mathrm{m}$ de pé-direito, $4,0 \mathrm{~m}$ de altura no ponto mais alto, 13,0 m de comprimento e 7,0 $\mathrm{m}$ de largura, coberta com filme de polietileno de baixa densidade transparente, aditivado anti-UV com espessura de $150 \mathrm{~m}$ e as laterais fechadas com tela antiafídeo.

$\mathrm{O}$ solo da área experimental foi originalmente classificado como Latossolo Vermelho Distroférrico, segundo a Embrapa (1999).

Foi empregado o delineamento em blocos casualizados (DBC), utilizaram-se cinco tratamentos e quatro repetições, perfazendo o total de 20 parcelas. Os tratamentos se constituíram de cinco lâminas de água, com base na evaporação do minitanque, sendo: W1, W2, W3, W4 e W5 referentes às lâminas de irrigação de 30, 60, 90, 120 e 150\% da evaporação do minitaque, respectivamente.

O minitanque tem a forma circular, construído em chapa galvanizada com $60,5 \mathrm{~cm}$ de diâmetro
(50\% do diâmetro do tanque Classe A), 25,4 cm de profundidade apoiado sobre estrado de madeira, este com altura de $15 \mathrm{~cm}$ acima do solo. O minitanque foi instalado no centro de uma das casas de vegetação.

As parcelas experimentais apresentaram as dimensões de $1,20 \mathrm{~m}$ de largura e 2,40 $\mathrm{m}$ de comprimento, totalizando uma área de $2,88 \mathrm{~m}^{2}$. Quatro linhas de plantas espaçadas $0,30 \mathrm{~m}$ entre linhas e $0,30 \mathrm{~m}$ entre plantas foram utilizadas, perfazendo o total de 32 por parcela, considerandose úteis as plantas das linhas centrais e descartando, nessas linhas, duas plantas no início e duas no final de cada parcela (parcela útil com $0,72 \mathrm{~m}^{2}$ e 8 plantas).

Utilizou-se de sistema de irrigação por gotejamento, sendo as linhas laterais compostas de emissores com vazão de $1,76 \mathrm{~L} \mathrm{~h}^{-1}$, diâmetro nominal (DN) $16 \mathrm{~mm}$ distanciados entre si a 0,30 $\mathrm{m}$, ficando posicionados na parcela, de forma a atender as duas fileiras de plantas, trabalhando com pressão de serviço em torno de $18 \mathrm{mca}$, que era regulada por meio de uma válvula reguladora de pressão inserida no cabeçal de controle. Utilizou-se também uma válvula solenóide para cada tratamento; tais válvulas eram acionadas por meio de um controlador programável (Total Control 12 Stations), previamente programado em cada irrigação, para funcionar o tempo necessário visando repor a lâmina de cada tratamento.

A lâmina de água aplicada com freqüência de dois dias, foi calculada considerando-se a porcentagem da evaporação $(\mathrm{K})$ medida no período previsto entre duas irrigações (2 dias), de acordo com cada tratamento e a eficiência de aplicação de água do sistema de irrigação, conforme a Eq. 1.

$$
\mathrm{LI}=\frac{\mathrm{EVm} \cdot \mathrm{K}}{\mathrm{E}}
$$

em que:

LI - lâmina de irrigação a ser aplicada em cada tratamento (mm); Evm - evaporação do minitanque 
medida no período $(\mathrm{mm}) ; \mathrm{Ei}$ - eficiência de aplicação de água do sistema $(0,90) ; \mathrm{K}$ - fração da evaporação de cada tratamento.

Obtiveram-se as diferentes lâminas de irrigação para cada tratamento, foram obtidas mediante diferentes tempos de funcionamento das linhas de gotejadores; este tempo foi obtido a partir da vazão média dos gotejadores, do espaçamento entre plantas e entre linhas de plantio, apresentado na Eq. 2.

$$
\mathrm{Ti}=\frac{\text { LI.Sp.Slp }}{\text { e.q }}
$$

em que:

Ti - tempo de irrigação para cada tratamento (h); LI - lâmina de irrigação a ser aplicada no tratamento (mm); Sp - espaçamento entre plantas (0,30 m); Slp - espaçamento entre linhas de plantas $(0,30 \mathrm{~m})$; e - número de emissores por planta $(0,5)$; q - vazão média do gotejador $\left(1,76 \mathrm{~L} \mathrm{~h}^{-1}\right)$.

A cultivar utilizada foi a Laureau, do tipo americana, por ser de grande aceitabilidade pelos produtores de Lavras e região e por apresentar elevada demanda pelas empresas de fast foods e consumidores. A adubação básica realizada vinte e um dias antes do transplantio, com base na análise química do solo e recomendações da quinta aproximação (GOMES; SILVA; FAQUIN, 1999).

Toda a adubação de cobertura foi realizada via fertirrigação seguindo-se também as recomendações da quinta aproximação (GOMES; SILVA; FAQUIN, 1999); os fertilizantes utilizados foram o Nitrato de Potássio, Nitrato de Cálcio e o Sulfato de Magnésio. O total de nutrientes fornecidos para a cultura, ou seja, a soma da adubação básica com a de cobertura, totalizou a quantidade em $\mathrm{kg} \mathrm{ha}^{-1} \mathrm{de}: 115,34 \mathrm{de} \mathrm{N}$; 79,20 de P; 173,76 de K; 115,46 de Ca; 12,20 de Mg e 15,60 de $\mathrm{S}$.

As mudas foram doadas por um produtor do município de Três Pontas, MG, as quais foram semeadas em bandejas de isopor de 288 células preenchidas com o substrato comercial Plantmax HT, específico para o cultivo da alface. Após 30 dias da semeadura, ocasião em que as mudas já se encontravam com quatro folhas definitivas, foi efetuado o transplantio para os canteiros.

Do transplantio, ocorrido em primeiro de novembro de 2008, até o início da diferenciação dos tratamentos (04/11) foram realizadas, por quatro dias, irrigações em todos os cinco tratamentos, totalizando uma lâmina de $24 \mathrm{~mm}$. Este procedimento teve como objetivo proporcionar um melhor "pegamento" e a uniformização no desenvolvimento inicial das mudas.

A colheita foi efetivada no dia 15 de dezembro de 2008, quando as plantas atingiram seu máximo desenvolvimento vegetativo, isto ocorre quando as cabeças da alface americana se encontram bem enfolhadas e compactas. As avaliações foram realizadas imediatamente após a colheita das parcelas úteis. Para a análise estatística das características físicas e produtivas da alface americana, considerouse a soma das irrigações feitas antes e após o início dos tratamentos, denominada lâmina total.

Para obtenção das características avaliadas as plantas foram pesadas, para estimativa da produtividade total, considerando-se 79.226 plantas por hectare. Para obter o peso total da cabeça comercial, as plantas foram desfolhadas até atingir o ponto ideal de comercialização. Para a estimativa da produção comercial, as cabeças de alface foram pesadas e convertendo-se os valores encontrados para $\mathrm{kg} \mathrm{ha} \mathrm{h}^{-1}$. Depois de pesada, procedeu-se à medida de sua circunferência com o auxilio de uma fita métrica. Foram retiradas as folhas internas da cabeça comercial, procedendo-se a sua contagem e pesagem e a eficiência do uso da água foi determinada pela relação entre os valores da produtividade total $\left(\mathrm{kg} \mathrm{ha}{ }^{-1}\right)$ e as respectivas quantidades de água consumidas em cada tratamento durante o cultivo. Os dados amostrados foram submetidos a análise de variância com a realização do teste $\mathrm{F}$ e análise de regressão a 5 e $1 \%$ de probabilidade, utilizando-se o programa SISVAR 4.0. 


\section{Resultados e Discussão}

No período de condução do experimento as médias de temperatura e a umidade relativa do ar no interior da casa de vegetação foram de $26,3^{\circ} \mathrm{C}$ e 55,4 $\%$, respectivamente. O referido valor de temperatura se encontra fora da faixa ótima recomendada por Santana, Almeida e Turco (2009), que relata a faixa 15 e $20^{\circ} \mathrm{C}$ como adequada ao bom desenvolvimento da alface, no entanto, relatam ainda que, quando cultivada em regiões de temperatura e luminosidade elevadas esta hortaliça deixa de desenvolver todo o seu potencial genético.

Para a análise estatística das características físicas e produtivas da alface americana, foi considerada somente a quantificação da lâmina aplicada durante a diferenciação dos tratamentos. O resumo da analise de variância das respectivas variáveis analisadas encontra-se descrito na Tabela 1.

Tabela 1. Resumo das análises de variância e de regressão quanto à produtividade total (PT), cabeça comercial (PCC), eficiência do uso da água (EUA), circunferência da cabeça comercial (CCC), altura de plantas (AP) e do número de folhas internas da cabeça comercial (NFI), em função de diferentes lâminas de irrigação. Lavras, UFLA, MG, 2008.

\begin{tabular}{ccccccc}
\hline \multirow{2}{*}{$\begin{array}{c}\text { Fonte de } \\
\text { Variação }\end{array}$} & G.L. & $\begin{array}{c}\text { PT } \\
\left(\mathrm{t} \mathrm{ha}^{-1}\right)\end{array}$ & $\begin{array}{c}\text { PCC } \\
\left(\mathrm{t} \mathrm{ha}^{-1}\right)\end{array}$ & $\begin{array}{c}\text { EUA } \\
\left(\mathrm{kg} \mathrm{ha}^{-1} \mathrm{~mm}^{-1}\right)\end{array}$ & $\begin{array}{c}\text { CCC } \\
(\mathrm{cm})\end{array}$ & $\begin{array}{c}\text { NFI } \\
(\mathrm{un} .)\end{array}$ \\
\hline Lâmina & 4 & $88,7793^{* *}$ & $44,3327^{* *}$ & $484245,50^{* *}$ & $13,226^{*}$ & $2,7451^{*}$ \\
Bloco & 3 & $2,3013^{\text {ns }}$ & $8,7672^{\text {ns }}$ & $779,0348^{\mathrm{ns}}$ & $1,7666^{\mathrm{ns}}$ & $0,4638^{\text {ns }}$ \\
Resíduo & 12 & 7,2280 & 7,1326 & 939,7010 & 2,8161 & 0,6215 \\
\hline Média & - & 61,20 & 32,34 & 546,25 & 55,75 & 16,44 \\
C.V. (\%) & - & 4,39 & 8,26 & 5,61 & 3,01 & 4,80 \\
\hline Linear & 1 & $1,5548^{\text {ns }}$ & $4,0990^{* *}$ & $1732146,12^{* *}$ & $22,1231^{*}$ & $1,0748^{\text {ns }}$ \\
Quadrática & 1 & $310,017^{* *}$ & $142,334^{* *}$ & $192455,61^{* *}$ & $22,8404^{*}$ & $9,0934^{*}$ \\
Desvios & 2 & $21,7522^{\text {ns }}$ & $15,4485^{\text {ns }}$ & $6190,14^{* *}$ & $3,9713^{\text {ns }}$ & $0,4062^{\text {ns }}$ \\
\hline
\end{tabular}

Em que: ns - não significativo pelo teste $\mathrm{F},{ }^{*} \mathrm{e}^{* *}$ - significativos a 5 e $1 \%$ de probabilidade pelo teste $\mathrm{F}$, respectivamente.

Fonte: Elaboração dos autores.

No caso da produtividade total e comercial, as variações ocorridas podem ser explicadas por uma regressão quadrática, tendo a mesma apresentado maior coeficiente de determinação $\left(R^{2}\right)$ para as duas variáveis, como pode ser visto na Figura 1A. A resposta quadrática indica que houve um acréscimo na produtividade total e comercial da cabeça, à medida que se aumentaram as lâminas de irrigação. O ponto máximo para a produtividade total foi estimado com uma lâmina de $159,1 \mathrm{~mm}$, referente à um fator de reposição (FR) de $95 \%$, equivalente a uma produtividade para esta variável de $66,9 \mathrm{t} \mathrm{ha}^{-1}$. Já para a produtividade da cabeça comercial, o ponto máximo foi atingido com a aplicação da lâmina de irrigação de 164,8 mm (FR de $98 \%$ ), resultando em uma produtividade para este parâmetro de $36,5 \mathrm{t} \mathrm{ha}^{-1}$.
Andrade Junior e Klar (1997) obteve, com a aplicação de 142,3 mm na cultivar Mesa 659, o máximo de produtividade de $90 \mathrm{t} \mathrm{ha}^{-1}$, sob cultivo protegido. Esse valor máximo correspondeu a lâminas aplicadas a cada dois dias, referentes a 75\% da evaporação do tanque Classe A. Para valores de lâminas acima de $75 \%$ da evaporação do tanque Classe A, houve redução no peso total por planta. $\mathrm{Na}$ mesma linha de pesquisa, Lima Junior et al. (2010) encontraram máxima produtividade comercial, 35,8 t ha-1 cultivar Raider plus, obtida com a aplicação da lâmina de 204,3 mm, correspondente ao fator de reposição de $101 \%$. Esse resultado foi inferior ao encontrado neste trabalho, podendo ser justificado pela cultivar utilizada pelos autores e também pela época do ano onde foi realizado o experimento. 
Figura 1. Valores médios, observados e estimados, da produtividade total e comercial (A), circunferência (B), número de folhas internas (C) e eficiência no uso da água (D) da alface americana, em função das lâminas de irrigação. Lavras, UFLA, MG, 2008.

A
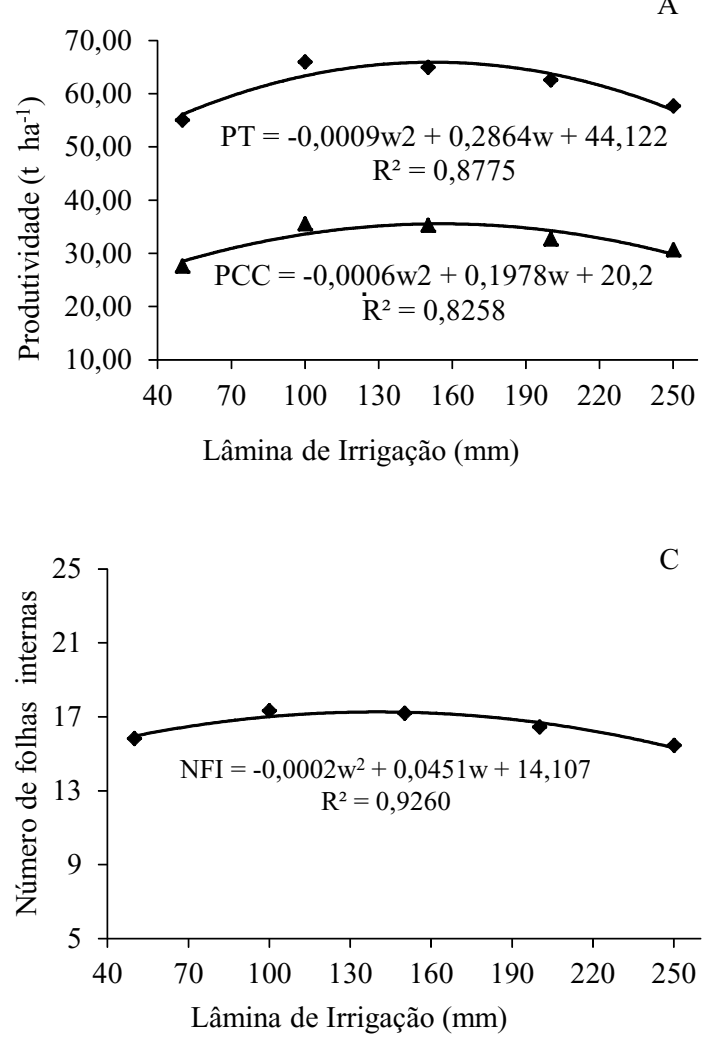

Fonte: Elaboração dos autores.

Verifica-se que os resultados encontrados neste trabalho estão abaixo do encontrado por Santos e Pereira (2004) para produtividade total e comercial da alface americana, valores máximos de 71,2 e $49,4 \mathrm{t} \mathrm{ha}^{-1}$, irrigando-se quando a tensão de água no solo, a $15 \mathrm{~cm}$ de profundidade, estava em torno de $15 \mathrm{kPa}$. A lâmina total de irrigação fornecida foi de $152,7 \mathrm{~mm}$.

Vilas Boas et al. (2007) encontrou valores máximos de produtividade total e comercial em experimento com alface crespa, irrigado por gotejamento, de 36,5 e 33,2 t ha-1, com aplicação das lâminas 249,1 e 244,9 mm para produtividade total e comercial, respectivamente.

Observa-se pela curva que houve redução na PT e na PCC com a aplicação da lâmina de 285,63 $\mathrm{mm}$, correspondente ao tratamento de 1,5 da lâmina
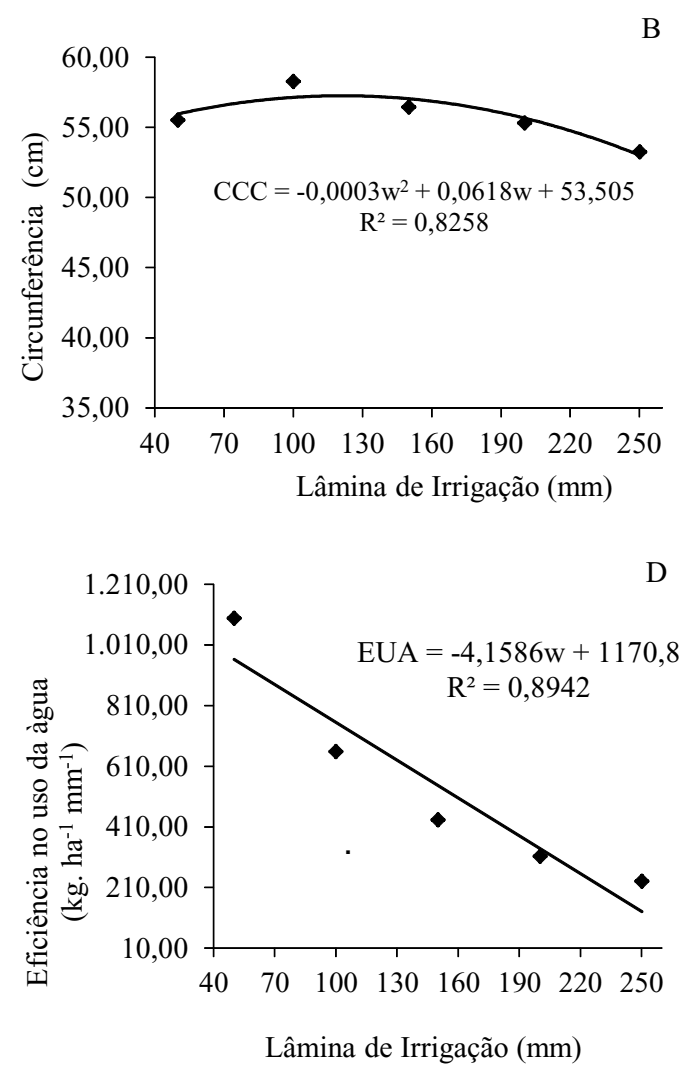

evaporada (W5). Esse fato deve possivelmente ter ocorrido devido ao excesso de umidade em torno do sistema radícular da planta, dificultando o arejamento, provocando assim, anomalias de origem fisiológicas, bem como a lixiviação de nutrientes. Assim, onera a cultura, sem nenhum beneficio, representando também um desperdício de água e energia, dois sérios problemas no mundo atual (FILGUEIRA, 2008).

As variáveis de circunferência da cabeça comercial (CCC), altura de plantas (AP) e número de folhas internas (NFI) apresentaram resposta quadrática em relação às lâminas de irrigação (Tabela 1).

$\mathrm{O}$ efeito quadrático da aplicação (Figura 1B e 1C) de água no solo apresentou um acréscimo nas variáveis analisadas (CCC e NFI), à medida que se 
aumentaram as quantidades de água aplicadas, até as lâminas de 103 e $112,7 \mathrm{~mm}$, que equivale a 62 e $67 \%$ da lâmina de reposição, respectivamente. A aplicação das laminas máximas resultaram em máximos de 58,35 $\mathrm{cm}$ para CCC e 16,65 para NFI. Assim, a umidade no solo favoreceu, de forma direta, o desenvolvimento vegetativo dessa cultura, até certo ponto, e a partir daí o acréscimo da lâmina de irrigação reduziu os parâmetros vegetativos em estudo.

A circunferência da cabeça comercial e um dos parâmetros básicos na aquisição do produto para obter elevados rendimentos no processamento; logo, esta característica serve como indicativo de seleção no momento de aquisição do produto pelos fornecedores. Esta mesma característica é um requisito básico quando se refere à preferência do consumidor para a aquisição do produto.

Silva et al. (2008) obteve o mesmo efeito quadrático para circunferência da cabeça comercial da alface americana, cujo valor máximo de circunferência foi de $44,94 \mathrm{~cm}$, com uma lâmina total de água de $170,81 \mathrm{~mm}$, correspondente a $91,66 \%$ da lâmina de reposição.

Santos e Pereira (2004), estudando o efeito de diferentes tensões de água no solo sobre o comportamento produtivo da alface americana, cv. Raider, em ambiente protegido, encontrou o máximo de 22,25 folhas internas por planta para a tensão de $15 \mathrm{kPa}$ com uma lâmina de água aplicada de $152,7 \mathrm{~mm}$, sendo este valor de lâmina superior ao encontrado neste trabalho. Mota et al. (1999) comenta que se a cabeça da alface americana estiver compacta, o aumento no número das folhas internas é uma característica desejável para a indústria, pois favorece o tamanho da cabeça comercial, bem como o aumento de sua massa.

De acordo com a Figura 1D, verifica-se que a eficiência no uso da água apresentou efeito linear decrescente com as lâminas de irrigação aplicadas a $1 \%$ de significância. À medida que os níveis de irrigação aumentaram, ocorreu uma diminuição na eficiência no uso da água. Ainda pode-se observar que $98,94 \%$ das variações ocorridas, na eficiência no uso da água em função das lâminas de irrigação aplicadas, são explicadas pela regressão linear simples. O mesmo comportamento foi verificado na cultura da alface por Vilas Boas et al. (2007) e Andrade Júnior e Klar (1997), quando da utilização de lâminas maiores a eficiência tende a decrescer até seu ponto mínimo, atingido seu máximo com lâminas menores. Sá et al. (2005), trabalhando com tensões de água no solo em ambiente protegido, cultivado com tomate, observou que a eficiência de uso da água apresentou resposta linear crescente, com o aumento dos valores de tensão.

Os valores de eficiência no uso da água variaram de $962,45 \mathrm{~kg} \mathrm{ha}^{-1} \mathrm{~mm}^{-1}$ a $130 \mathrm{~kg} \mathrm{ha}^{-1} \mathrm{~mm}^{-1}$, com as lâminas de irrigação de 50,1 mm e 250,20 mm, respectivamente. Observa-se ainda que, para a lâmina de 150,2 mm, correspondente a $90 \%$ da lâmina de reposição, obteve um rendimento de $546.17 \mathrm{~kg} \mathrm{ha}^{-1} \mathrm{~mm}^{-1}$, esta última considerada como ponto médio dentro do intervalo válido para essas observações.

\section{Conclusões}

Diante das condições em que o experimento foi desenvolvido e dos resultados obtidos para a cultura da alface americana pode-se concluir que:

1 - a máxima produtividade comercial, 36.502 $\mathrm{kg} / \mathrm{ha}$, foi estimada com a aplicação da lâmina de $164,8 \mathrm{~mm}$, correspondente ao fator de reposição de $98 \%$;

2- a maior eficiência no uso da água $(962,45$ $\mathrm{kg} / \mathrm{ha} / \mathrm{mm}$ ) ocorreu com a aplicação da lâmina de irrigação de $50,10 \mathrm{~mm}$, correspondente ao fator de reposição de água de $30 \%$; 


\section{Referências}

AGRIANUAL 2008. Anuário da agricultura brasileira: alface. São Paulo: FNP, 2008. p. 345.

ANDRADE JÚNIOR, A. S. de; KLAR, A. E. Manejo da irrigação da cultura da alface (Lactuca sativa $\mathrm{L}$.) através do tanque classe A. Scientia Agricola, Piracicaba, v. 54, n. 1-2, p. 31-38, jan./ago. 1997.

DANTAS, A. A. A; CARVALHO, L. G.; FERREIRA, E. Classificação e tendência climática em Lavras, MG. Ciência e Agrotecnológia, Lavras, v. 31, n. 6, p. 18621866, nov./dez. 2007.

EMPRESA BRASILEIRA DE PESQUISA AGROPECUÁRIA - EMBRAPA. Centro Nacional de Pesquisa de Solos. Sistema brasileiro de classificação de solos. Rio de Janeiro: Embrapa Solos, 1999. 412 p.

FILGUEIRA, F. A. R. Novo manual de olericultura: agrotecnologia moderna na produção e comercialização de hortaliças. 3. ed. Viçosa, MG: UFV, 2008. 421 p.

GOMES, L. A. A.; SILVA, E. C. da; FAQUIN, V. Recomendações de adubação para cultivos em ambiente protegido. In: RIBEIRO, A. C.; GUIMARÃES, P. T. G.; ALVAREZ., V. H. (Ed.). Recomendações para o uso de corretivos e fertilizantes em minas gerais (5 aproximação). Viçosa, MG: UFV, 1999. p. 99-110.

KOETZ, M.; COELHO, G.; COSTA, C. C. C.; LIMA, E. P.; SOUZA, R. J. Efeito de doses de potássio e da freqüência de irrigação na produção da alfaceamericana em ambiente protegido. Engenharia Agrícola, Jaboticabal, v. 26, n. 3, p. 730-737, 2006.

LIMA JUNIOR, J. A.; PEREIRA, G. M.; GEISENHOFF, L. O.; COSTA, G. G.; VILAS BOAS, R. C.; YURI, J. E. Efeito da irrigação sobre o efeito produtivo da alface americana, em cultivo protegido. Revista Brasileira de Engenharia Agrícola e Ambiental, Campina Grande, v. 14, n. 8, p. 797-803, 2010.

MOTA, J. H.; SOUZA, R. J. S.; SILVA, E. C.; CARVALHO, J. G.; YURI, J. E. Efeito do cloreto de potássio via fertirrigação na produção de alface-americana em cultivo protegido. Ciência e Agrotecnologia, Lavras, v. 25, n. 3, p. 542-549, 1999.

OLIVEIRA, A. C. B.; SEDIYAMA, M. A. N.; PEDROSA, M. W.; GARCIA, N. C. P.; GARCIA, S. L. R. Divergência genética e descarte de variáveis em alface cultivada sob sistema hidropônico. Acta Scientiarum, Maringá, v. 26, n. 2, p. 211-217, 2004.
SÁ, N. S. A.; PERREIRA, G. M.; ALVARENGA, M. A. R.; MATTIOLI, W.; CARVALHO, J. A. Comportamento da cultura do tomateiro sob diferentes tensões de água no solo em ambiente protegido. Revista Brasileira de Engenharia Agrícola e Ambiental, Campina Grande, v. 9, n. 3, p. 341-347, 2005.

SANTANA, C. V. S.; ALMEIDA, A. C.; TURCO, S. H. N. Produção de alface roxa em ambientes sombreados na região do submédio São Francisco - BA. Revista Verde de Agroecologia e Desenvolvimento Sustentável, Mossoró, v. 4, n. 3, p. 1-6, 2009.

SANTOS, S. R.; PEREIRA, G. M. Comportamento da alface tipo americana sob diferentes tensões da água no solo, em ambiente protegido. Engenharia Agrícola, Jaboticabal, v. 24, n. 3, p. 569-577, set./dez. 2004.

SEGOVIA, J. F. O.; ANDRIOLO, J. L.; BURIOL, G. A.; SCHNEIDER, F. M. Comparação do crescimento e desenvolvimento da alface (Lactuca sativa L.) no interior e exterior de uma estufa de polietileno em Santa Maria - RS. Ciência Rural, Santa Maria, v. 27, n. 1, p. 37-41, 1997.

SILVA, P. A. M.; PEREIRA, G. M.; REIS, R. P.; LIMA, L. A.; TAVEIRA, J. H. S. Função de resposta da alface americana aos níveis de água e adubação nitrogenada. Ciência e Agrotecnológia, Lavras, v. 32, n. 4, p. 12661271, 2008.

VILAS BOAS, R. C.; CARVALHO, J. A.; GOMES, L. A. A.; SOUZA, K. J.; RODRIGUES, R. C.; SOUSA, A. M. G. Efeito da irrigação no desenvolvimento da alface crespa, em ambiente protegido, em Lavras, MG. Revista Brasileira de Engenharia Agrícola e Ambiental, Campina Grande, v. 11, n. 4, p. 393-397, 2007.

VOLPE, C. A.; CHURATA-MASCA, M. G. C. Manejo da irrigação em hortaliças: método do tanque Classe A. Jaboticabal: FUNEP, 1988. 19 p.

YURI, J. E.; MOTA, J. H.; RESENDE, G. M.; SOUZA, R. J.; RODRIGUES JÚNIOR, J. C. Desempenho de cultivares de alface tipo americana em cultivo de outono no sul de minas gerais. Ciência e Agrotecnológia, Lavras, v. 28 , n. 2, p. 282-286, 2004.

YURI, J. E.; SOUZA, R. J. de; FREITAS, S. A. C. de; RODRIGUES JÚNIOR, J. C.; MOTA, J. H. Comportamento de cultivares de alface tipo americana em Boa esperança. Horticultura Brasileira, Brasília, v. 20, n. 2, p. 229-232, 2002. 